\section{Knowledge transfer and translation in cultural ecosystems}

Knowledge in cultural ecosystems

\author{
Renata Paola Dameri \\ Department of Economics and Business, University of Genoa, Genoa, Italy, and \\ Paola Demartini \\ Department of Business Studies, University of Roma Tre, Roma, Italy
}

\begin{abstract}
Purpose - This paper concerns the pivotal role that entrepreneurial universities can play in developing knowledge transfer and translation processes tailored to the cultural ecosystem.

Design/methodology/approach - The paper examines IncubiAmo Cultura, an innovative project that aims to mentor potential entrepreneurs and offer incubation and acceleration for cultural start-ups. The research methodology is based on action research and theory building from cases. An interventionist approach has been adopted, as one of the authors is also the founder of the ongoing project.

Findings - The in-depth collection of first-hand information on this pilot project has allowed the authors to formulate an analytical reflection and generate the design of a knowledge translation model driven by an entrepreneurial university that manifests itself through the creation of cultural and creative start-ups.

Research limitations/implications - This article offers an original contribution to scholarship by offering a conceptual model for knowledge translation in cultural ecosystems. Common values (i.e. social, cultural, ethical and aesthetic ones) emerge as the basis on which to build open innovation and knowledge circulation. Practical implications - For local policymakers, this study provides a clue to understand the need for both an integrated vision of knowledge translation and policies that aim to make an impact at the cultural ecosystem level. For entrepreneurial university governance, our investigation offers suggestions on the design and implementation of knowledge translation processes that fit with the specificity of the cultural ecosystem. For practitioners in the cultural field, a change of mindset is required to combine resources, energies and knowledge. Originality/value - This work fills several gaps in the literature, as research generally concerns knowledge transfer from entrepreneurial universities to the market with regard to high-tech sectors. In contrast, the cultural sector is often neglected, despite its importance in the renewal and development of a territory.
\end{abstract}

Keywords Cultural ecosystems, Cultural and creative start-ups, Cultural heritage, Entrepreneurial university, Knowledge transfer, Knowledge translation

Paper type Research paper

\section{Introduction}

This paper concerns the pivotal role that entrepreneurial universities can play in fostering cultural entrepreneurship, thanks to knowledge transfer and translation processes tailored to the cultural ecosystem (Borin and Donato, 2015; Holden, 2015; Fish et al., 2016).

Despite the difficulties in finding a single definition of the entrepreneurial university, several attempts have been made to define it in literature, and it is possible to identify several common features that distinguish the entrepreneurial style (OECD, 2012). An entrepreneurial university (Clark, 2001; Etzkowitz, 2003; Guerrero and Urbano, 2012) implies the emergence of third mission (Gulbrandsen and Slipersaeter, 2007), which is incremental to the traditional and consolidated ones of education and research, and requires direct involvement in the exploitation of research results, intense collaborations with the industry and involvement in regional social and economic development (Yusof and Jain, 2010; Astebro and Bazzazian, 2011;

(C) Renata Paola Dameri and Paola Demartini. Published by Emerald Publishing Limited. This article is published under the Creative Commons Attribution (CC BY 4.0) licence. Anyone may reproduce, distribute, translate and create derivative works of this article (for both commercial and non-commercial purposes), subject to full attribution to the original publication and authors. The full terms of this licence may be seen at: http://creativecommons.org/licences/by/4.0/legalcode
1885

Received 29 October 2019 Revised 7 June 2020 16 July 2020

20 August 2020

Accepted 2 October 2020

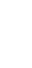


Secundo et al., 2017). Moreover, an entrepreneurial university is well rooted in the regional entrepreneurial ecosystem (Pugh et al., 2019), and its impact affects both internal stakeholders (students, graduates, staff) and external ones (local business, organisations), including the whole community.

In this vein, entrepreneurial universities, given their nature as a knowledge hub (Rice $e t$ al., 2014), are widely seen as vital actors of the ecosystem (Guerrero et al., 2016). Insofar, the main streams of research has investigated the role of the university rooted in knowledge production, transfer and translation into practice referring to academic spin-offs set up to commercialise the research results, through cooperation with firms and institutions (Friedman and Silberman, 2003; Hayter, 2016).

However, all these studies have been focusing on the translation to the practice of "knowledge", almost conceived as "technology". Similarly, it is implied that knowledge transfer from the university to the market or community means "technology transfer" (Wright, 2014; Cocchia and Dameri, 2016; Secundo et al., 2016a). On the contrary, we deem that the pivotal role played by the university in translating knowledge to action can be exploited more broadly, and in particular in the cultural ecosystem.

A cultural ecosystem is an environment in which different actors (i.e. public and private organisations, associations, communities, artists, creative people, citizens), interested in producing and consuming arts and culture, interact, and an entrepreneurial university can act as a hub to activate and foster relationships and as an engine for leveraging talent (Florida, 1999). Until now, the role of the entrepreneurial university in supporting the spur of cultural start-ups and projects has been neglected both in practice and by the literature.

In this context, the university's role goes beyond traditionally supporting entrepreneurship by engaging in learning and knowledge transfer activities that connect universities with businesses in their locality and regions and that also involve cultural actors in creating and evaluating business opportunities in the cultural sector and exploit them to create economic and social value concurrently (Pugh et al., 2019).

In this paper, we aim to fill this lack by demonstrating that this role can be successfully played by entrepreneurial universities that mix research and educational competence combining public and private institutional logics, as no large companies or other actors have the competence or are interested in promoting cultural spillover as it happens in the high-tech sector (Rasmussen and Lynov, 2005).

Similarly, the scarce literature available on the knowledge flow within a cultural ecosystem (Borin and Donato, 2015; Petrova, 2018) highlights how the presence of multiple actors of different types but complementary for the achievement of common cultural goals and projects, favours a climate of trust and collaboration, as opposed to competition, which can translate into knowledge sharing and open innovation. Hence, this paper aims to contribute to the emerging research on cultural ecosystem knowledge flows by designing a conceptual model that explores the knowledge translation processes that can be activated by an entrepreneurial university and tailored to the spur of cultural start-ups and initiatives.

Indeed, this issue deserves attention and has gained momentum for the potential cultural, social and environmental impacts generated by cultural ventures, which, as a result, enhance artistic creativity, social inclusion, well-being and urban regeneration (Cooke and Lazzeretti, 2008; Degen and García, 2012; Un, 2013).

This work presents longitudinal research that has been investigated since January 2016 and is still in progress. The research methodology is based on action research (Lewin, 1946; Glaser Barney and Strauss Anselm, 1967) and theory building from cases (Yin, 1994; Eisenhardt, 1989; Eisenhardt and Graebner, 2007); the paper analyses a case study that implements an innovative project that aims to nurture education, mentoring and cultural start-up incubators and accelerators with a participatory multi-actor approach. From a methodological point of view, the study was carried out in the light of interventionist 
research, as one of the authors is also the founder of the project and plays the double role of academic orchestrator and project manager.

Our study envisages a pivotal role of the university in designing and implementing specific knowledge flows in cultural ecosystems. Knowledge is not simply transferred to the market but conveyed in a circular movement from the university to the cultural ecosystem and back, thanks to the academic work and collaboration with local stakeholders (Leardini et al., 2017).

This paper is structured as follows: Section 2 illustrates the literature review on knowledge flow within a cultural ecosystem and how the entrepreneurial university can play a pivotal role to highlight the research framework; the methodology and main findings are presented in Sections 3 and 4, respectively. Section 5 draws on results and provides the design of a conceptual model for knowledge translation, while Section 6 highlights implication for research, policymakers and practitioners; finally, by recalling the limits of this study, directions for further research are also provided.

\section{Literature review and research framework}

While scrutinising the literature, we found it useful to look for thoughts and concepts in two different streams of research:

(1) First, we underlined the main features of the flow of knowledge within a cultural ecosystem, and highlighted the main differences concerning knowledge transfer in the mainstream literature.

(2) Second, we recalled the concept of the entrepreneurial university as a collective intelligent system because we deem that it is useful to elicit the aptitude of such an organisation to act as a cultural mediator and knowledge catalyst in a cultural ecosystem. In so doing, we highlighted the knowledge translation processes that universities can leverage on to foster cultural entrepreneurship.

\subsection{The flow of knowledge within a cultural ecosystem}

In recent years, local cultural ecosystems have emerged as a new way to conceive the cultural and creative sector with regard to its territory (Borin and Donato, 2015; Holden, 2015). Indeed, the shift of the governance model of the cultural sector from a "micro" perspective to a "meso" perspective, involving multiple partners and stakeholders, seems to manage better with the traditional reliance of the sector on public funding and private sponsorships (Bonet and Donato, 2011; Borin et al., 2018) and with the new opportunities offered by regional projects of culture-led regeneration and development (Sacco and Tavano Blessi, 2009; Petrova, 2018). Accordingly, the comprehension of knowledge flow mechanisms inside the local ecosystems is crucial in developing its potential.

To understand the specificities of how knowledge flows within a cultural ecosystem, we need to analyse the units that constitute it. These units include not only private for profit and not-for-profit, public, hybrid organisations but also grassroots cultural movements, communities of artists or experts and passionate people that are motivated by rewards that go beyond mere economic aspects, including social, ethical and aesthetic benefits (Pagano et al., 2018; Schiuma, 2011).

Holden (2015) argued that culture should be studied with the canons of ecology rather than with the rules of economy. "Ecology" studies the relationships and vital connections between living organisms and their physical environment. The four main levels of study in ecology are the organism, population, community and ecosystem are dynamically interacting systems of organisms, the communities they make up and the components of their environment.

For our purposes, it is worthwhile to highlight that ecologists seek to explain: (1) interactions, interrelationships, behaviours and adaptations of organisms; (2) the movement of energy through living communities; (3) the development of ecosystems.
Knowledge in cultural ecosystems

1887 
$\mathrm{MD}$

58,9

By analogy, we can state that, according to the scarce literature on cultural ecosystems, the latter have a strong territorial component and emerge based on the values and cultural identity the different members share (Borin and Donato, 2015; Borin and Delgado, 2018). Creativity and passion (which is what the energy of a cultural ecosystem is made of), flow among the different organisms and communities, which have blurred boundaries, changing according to the interactions and interplay of the different actors driven by specific and sometimes temporary cultural projects (i.e. a festival, an exhibition, etc.). Interaction between the players also includes knowledge enabled by common cultural values (Throsby, 1999) and cultural interests (Birnkraut, 2018), close collaborations and mutual learning (Petrova, 2018) and trust-based personal contacts within the cultural ecosystem (Secundo and Schiuma, 2018). The co-presence of cultural, social and economic objectives is a prerogative of the actors' mission of a cultural ecosystem and characterises them as hybrids, regardless of the organisational form adopted (Haigh et al., 2015). Indeed, hybrids are oriented to complement rather than compete with actors they perceive to be driven by similar societal goals (Hockerts, 2015). Hence, as affirmed by Lee and Jay (2015), the benefits of such a "non-zero sum competition" mindset include that hybrids serve as incubators for new practices that can then gain scale and impact when infused into the collaborating firm.

Even for the mainstream literature on knowledge transfer, which in most cases refers to the tech sector, relationships between individuals and social interactions among organisational members play a fundamental role in favouring knowledge circulation (Kogut and Zander, 1992; Grigoriou and Rothaermel, 2014). However, the main differences with the cultural ecosystem knowledge flow essentially consist in the different drivers of knowledge transfer and in the existence of companies with defined boundaries, which characterise the flow of knowledge inside and outside organisations (Savino et al., 2017).

The reasons for knowledge transfer stem from the search for innovation, enhancing the competitiveness of companies (Kogut and Zander, 1993). The issues are to identify how the circulation of ideas and the integration of various knowledge within the firm can be facilitated (Verona and Ravasi, 2003) and detect the most effective and efficient methods of research and acquisition of knowledge within clusters/districts/entrepreneurial ecosystems or through collaboration with particular stakeholders, among whom the University plays a fundamental role (Laursen and Salter, 2004; Fontana et al., 2006; Köhler et al., 2012; Simeone et al., 2017a, b).

Moreover, extant research has demonstrated that transferring knowledge across the firm's external boundary is more difficult than transferring knowledge throughout the firm (Nakauchi et al., 2017). This difficulty is due to conflicts of interest and knowledge protection strategies, lack of trust (Kachra and White, 2008) and difficulties in sharing a common language (Zander and Kogut, 1995).

All these rationales cannot be applied tout court to a cultural ecosystem in which individuals, communities and organisations are often involved in temporary participatory cultural initiatives in various ways (Biondi et al., 2020) and share language, interests and goals (Piber et al., 2019). Moreover, knowledge is conceived as a common good, to be shared as much as possible, and not as an asset to be kept hidden and exclusive through intellectual property rights (Dameri and Moggi, 2019).

In general, it can be said that in previous studies, most researchers focused on individual knowledge transferred within a dyad relationship rather than focusing on knowledge collectively held and transferred (Nakauchi et al., 2017), which, conversely, is a typical feature of a cultural ecosystem (Pagano et al., 2018; Petrova, 2018).

In summary, on the basis of our literature review we deem that knowledge transfer takes on a different meaning within a cultural ecosystem, because it takes place within a community of actors that aggregates for common interests and purposes, almost driven by a hybrid mission that aims to reach cultural, economic and social goals (see Table 1). Cultural events or culture-led urban regeneration projects are examples of how various actors of a 
cultural ecosystems can join, promoting the exchange while also the sharing of knowledge and other tangible and intangible resources and originating innovative collaborative solutions with a win-win logic.

\subsection{The entrepreneurial university as a collective intelligent system}

The characteristics of a cultural ecosystem, in which a plurality of actors who share the same cultural identity coexist and are ready to collaborate in common projects, can offer an entrepreneurial university grounds for experimentation.

Indeed, some scholars argue that the role of entrepreneurial academics is to seek new ways to engage with the community to create value for society (Botes, 2005; Kingma, 2011; Fayolle and Redford, 2014).

Universities have played a crucial role in the innovation ecosystem, almost leveraging hard sciences and high-tech knowledge (for a review, see: Powell and Snellman, 2004). However, the contribution that universities can offer is also that of acting as "cultural mediators" among different stakeholders in a multilevel network, from the individual to the micro and the meso level (Simeone et al., 2017a, b). Thanks to devoted organisational units (i.e. Laboratories, knowledge and TTO units, accelerators and incubators, etc.) and specific techniques (i.e. design process and art-based initiatives), universities can translate distinct and complex knowledge into a common language for stakeholders with different needs, interests, goals and languages. In so doing, universities enable the sharing, transfer and creation of knowledge (Simeone et al., 2017a, b; Simeone et al., 2018).

The concept of the university as a collective intelligent system (Secundo et al., 2016b; 2018) elicits that knowledge is no longer only accumulated and created within the university, as an ivory tower, but is co-created by different actors of an ecosystem through collective intelligence. The term "collective" describes a group of individuals that work together to find solutions to a given problem. The term "Intelligence" refers to the ability to learn, understand and adapt to an environment by using knowledge (Leimeister, 2010). Therefore, in an entrepreneurial university, the focus shifts from the processes of internal creation of knowledge (Etzkowitz, 2003) to the processes of creating relational capital and social capital (Paoloni et al., 2019). Hence, interdependencies and knowledge flows between different stakeholders become crucial.

Until now, the role that the entrepreneurial university can play in supporting the development of a cultural ecosystem has been neglected by the literature with only some exceptions regarding the mere description of specific case studies of University-Based Arts Venture Incubators (Essig, 2014a, b).

Referring to a cultural ecosystem, the lack of an entrepreneurial mind-set and managerial skills of the public officers involved in the cultural sector (Borin and Donato, 2015, p. 295), as

\begin{tabular}{|c|c|c|}
\hline & $\begin{array}{l}\text { Knowledge transfer in the mainstream } \\
\text { literature }\end{array}$ & $\begin{array}{l}\text { Knowledge transfer in the cultural } \\
\text { ecosystem literature }\end{array}$ \\
\hline Focus & $\begin{array}{l}\text { Focus on individual knowledge transferred } \\
\text { within a dyad relationship }\end{array}$ & $\begin{array}{l}\text { Focus on knowledge collectively held and } \\
\text { transferred }\end{array}$ \\
\hline $\begin{array}{l}\text { Knowledge } \\
\text { flow }\end{array}$ & Unidirectional or bidirectional & $\begin{array}{l}\text { Multi-actors exchanges. Knowledge } \\
\text { sharing within specific communities }\end{array}$ \\
\hline $\begin{array}{l}\text { Knowledge } \\
\text { exchange }\end{array}$ & $\begin{array}{l}\text { Based on research activities and regulated } \\
\text { by knowledge protection strategies }\end{array}$ & $\begin{array}{l}\text { Based on experience and facilitated by } \\
\text { friendly relationships }\end{array}$ \\
\hline $\begin{array}{l}\text { Knowledge } \\
\text { flow context }\end{array}$ & $\begin{array}{l}\text { Transferring knowledge across the firm's } \\
\text { external boundary can be difficult due to } \\
\text { conflicts of interest and competition on the } \\
\text { market }\end{array}$ & $\begin{array}{l}\text { Knowledge transfer and innovative } \\
\text { practices driven by collaborating } \\
\text { opportunities which unfold over time } \\
\text { (i.e. cultural events, exhibitions, urban } \\
\text { regeneration projects, etc.) }\end{array}$ \\
\hline
\end{tabular}

Knowledge in cultural ecosystems 
$\mathrm{MD}$

58,9

well as the lack of entrepreneurial and managerial competence of cultural entrepreneurs, whose studies are grounded in Arts and Humanities fields (Ellmeier, 2003), is a setback for the implementation of collaboration between private and public entities and, more broadly, a pitfall for both cultural ecosystems and regional development.

Hence, universities can play an important role by transferring entrepreneurial knowledge to potential cultural entrepreneurs. Meanwhile, universities, acting as a collective intelligent system, can collect and combine the widespread knowledge existing in the cultural ecosystem through a creation process of new cultural ventures, which in turn, can be actors of innovation and regeneration for the territory.

Under the latter perspective we deem that, within a cultural ecosystem, a university can translate into action widespread and fragmented knowledge of the sector between the different actors, directing it towards business projects and cultural initiatives. They can also act as a catalyst of energies and human resources, promoting formal and informal relationships between individuals and organisations.

Moreover, we are also concerned with understanding whether this process of knowledge translation can be seen as new opportunity to build common sensemaking based upon the dissemination of entrepreneurial and managerial "knowledge" among potential cultural entrepreneurs and other stakeholders involved in the university projects for the development of a cultural ecosystem.

In this vein, we wonder if such a project can be seen as an opportunity to design new cultural products, services and business models with the help of actors who play diverse roles (Bogers and Horst, 2014). In detail, potential entrepreneurs bring their creativity and energy embedded in their business idea; cultural experts and actual entrepreneurs bring their concrete experience, evaluate the feasibility of the business and act linking past tradition with innovation (De Massis et al., 2016); while academics mainly play the role of both consultants and mediators by facilitating common sensemaking (Strike and Rerup, 2016).

Accordingly, we wonder if a pitch desk or a business plan, i.e., artefacts created thanks to the collaboration between heterogeneous actors who have common identitary values, can be a combination of innovation and traditional expertise in the cultural field (Magistretti et al., 2020). Hence, they act as boundary objects to represent and accumulate knowledge from a wide variety of stakeholders (Bogers and Horst, 2014).

Table 2 summarises the two meanings of knowledge translation mentioned above have been elicited from literature analysis with regard to our research aim.

\subsection{Research gaps}

Drawing on the literature review developed within the two streams of research mentioned above, in this section, we will highlight the main emerging research gaps and opportunities for inquiry.

Table 2.

Knowledge translation processes driven by a university aiming to foster the spur of cultural entrepreneurship

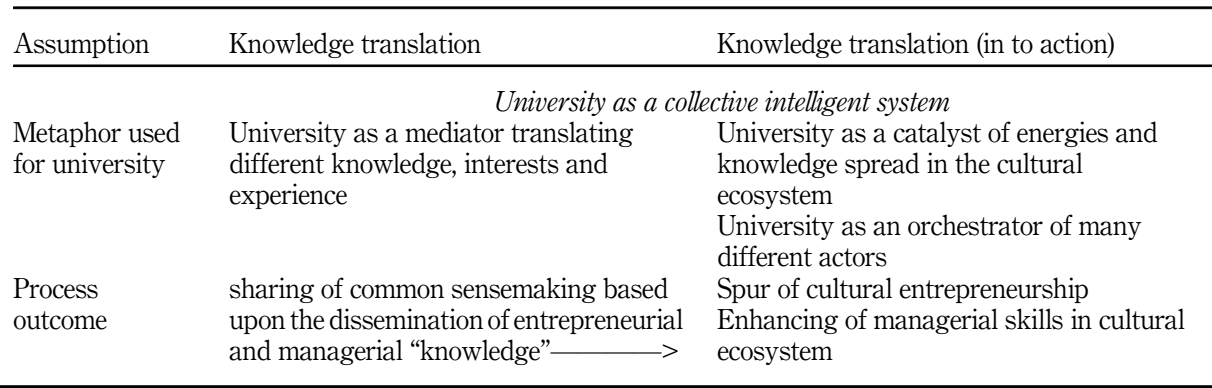


The first gap concerns the lack of inquiry on the role that an entrepreneurial university can play in building knowledge translation mechanisms in a cultural ecosystem. As previous literature on university knowledge translation has focused mainly on the hi-tech sector, we have investigated the specificity of the cultural sector, analysed under the conceptual lens of a cultural ecosystem. In so doing, we also aim to answer Borin and Donato's call (2015) for further research on actors and processes that can aggregate resources and energies spread and fragmented throughout local cultural ecosystems.

The second gap concerns the consequent need for a conceptual model that explores the process that an entrepreneurial university can play thanks to knowledge translation processes tailored to the spur of cultural start-ups and initiatives. Building on the literature review on universities as collective intelligent systems (Secundo et al., 2016b), we aim to design the knowledge flow processes activated by an entrepreneurial university, which have experimented to collect, combine and convey knowledge and support to cultural entrepreneurship for both competitiveness and quality of life in the territory.

The third gap concerns a need for understanding how the two following meanings of translating knowledge, elicited from our literature review, can be effectively deployed in a cultural ecosystem:

(1) Collect, share and recombine the knowledge scattered among the different actors to translate them into practices and

(2) Creating common language and sensemaking among the different stakeholders involved.

Hence, in order to fill the above-mentioned gaps, our in-field analysis aimed to answer the following research question: How can knowledge processes activated by an entrepreneurial university to foster cultural start-ups be designed, developed and perceived?

\section{Methodology}

\subsection{Research methodology}

This paper presents longitudinal research that has been investigated since January 2016 and is still in progress. The research methodology is based on action research (Lewin, 1946; Glaser Barney and Strauss Anselm, 1967), theory building from cases (Yin, 1994; Eisenhardt, 1989; Eisenhardt and Graebner, 2007) and the interventionist approach (Jö nsson and Lukka, 2006; Suomala, 2009).

Action research is a research strategy aiming at doing research and taking action concurrently, linked together thanks to a critical reflection (Lewin, 1946). The action is rooted in an experimental case of entrepreneurial university applied to the cultural sector. Its aim is to build theory from this case generating outcomes that are both relevant to practice and scholarly rigorous (Canterino et al., 2016), given that there are no extant theoretical conceptualisations, and only some descriptive case studies are available on this topic.

Building theory from cases involves creating theoretical constructs with the use of casebased empirical evidence (Eisenhardt, 1989). Theory can be built using a case study as an experiment from which to develop theory inductively (Eisenhardt and Graebner, 2007).

In interventionist research, at least one of the researchers is actively involved in the investigated field, moving in and out of the target organisation to collect observations and then develop new theoretical insights. In the present case, one of the authors is the founder and orchestrator of the initiative, whereas the other author is not involved in the project but contributes as an external observer and discussant (Jö nsson and Lukka, 2006). Thanks to their collaboration, the researchers were able to cross the border between the emic (insider) and etic (outsider) perspectives and overcome the limitation of interventionist approach, that is, its non-unobtrusive nature (Johnsson and Lukka, 2006). Moreover, thanks to a critical
Knowledge in cultural ecosystems 
approach, this study aims to produce contributions that are not only practically relevant but also theoretically significant (Suomala, 2009).

\subsection{Case selection}

Action research is based on a single case study that presents the characteristics of uniqueness (Yin, 1994) because it is one of the rare cases in which a university experimented an integrated knowledge translation process aiming to nurture entrepreneurial education, mentoring potential entrepreneurs and offering incubation and acceleration for students' cultural startups. Furthermore, researchers had direct and rich access to first-hand data and observations to bridge the gap between empirical evidence and conceptualisation. The emerging theory arises from a rare occasion to directly explore a significant phenomenon.

The case concerns a pilot project titled "IncubiAmo Cultura", a play on words: Incubator + Love + Culture. It was launched by a scholar, who, according to Meyer (2003), we can call "an entrepreneurial academic". This scholar designed and implemented an initiative that has led the University of Genoa to play a pivotal role in supporting new ventures in the cultural sector. The project was born to meet the cultural needs that emerged from the citizens of the city's degraded neighbourhoods, calling for urban regeneration.

During the last twenty years, the historical centre has been the subject of an extensive restoration program, driving Genoa to be included in the UNESCO World Heritage List, thereby starting a cultural rebirth of the city. As a result, Genoa is now a large laboratory of cultural renaissance, where start-ups and other private and public players, as well as civil society and citizens, are called to play an innovative role.

This case study is therefore an experiment chosen for its likelihood to offer both empirical and theoretical insights into a dynamic situation, promising to be further replicated in other contexts. The emerging theory arising from this experiment is articulated, further testable and permits the further application of the suggested conceptual model to validate the results of the present research (Siggelkow, 2007).

\subsection{Data collection and data analysis}

Data were collected from 2016 to 2019 by the authors, who acted as "participant-observers": given the aim of this study, the participant observation is deemed the most appropriate (Magistretti et al., 2020). Data collection and analysis can be classified according to the following three research steps: (1) Participation in the Forget heritage EU project; (2) University in action; (3) Institutionalisation of the project IncubiAmo Cultura.

The first step concerns the participation of the university in the EU Interreg project Forget Heritage, "aiming to identify innovative, replicable and sustainable public-private cooperation management models of the historical sites by valorising them through setting up cultural ventures", which offered the background to feed the following research phases. The project involved 10 partners, cities or Regions (Genoa IT, Nurberg DE, Ljubljana SL, Pecs HU, Rijeka KR, Usti nad Labem CZ, Warsawa PL, Region Lombardia IT, Slovenjia SL, Miasto PL). Data collection was carried on by researchers in each country, through semi-structured interviews with cultural entrepreneurs and actors involved in urban restoration programs. One hundred interviews were collected, decoded and summarised in shared tables by the project's team.

Best practices were identified and further analysed to extract the transferable elements in cultural heritage management; these elements are summarised in nine cards of best practice cultural start-ups and in the Analysis of the transferable elements (see FH1 website).

The interviews also brought out the educational gaps in management for aspirant cultural entrepreneurs and drove the definition of educational initiatives, summarised in the Transnational training model (see FH2 website). 
All these data were shared at 12 meetings: 6 of them involved only the representatives of the project partners, 6 others involved a large audience of public officials in cultural heritage and managers or entrepreneurs in the cultural sector. During these meetings, notes were collected (see FH3 website), then summarised in the Strategy of management of cultural heritage through cultural and creative firms (see FH4 website https://www.interreg-central.eu/ Content.Node/Forget-heritage.html).

The second step, defined university in action, regards the translation in action of the outcomes that emerged from step 1 and were finalised for the spur of cultural start-ups and initiatives. During this stage, data collection addressed the daily activities involving aspirant entrepreneurs in the cultural sectors and master students. Data regards unstructured dialogues with 140 aspirant entrepreneurs, especially focused on motivation and educational gaps; brainstorming with 47 master students, during their masterclasses, focused on business ideas and their progress in learning, and there were three meetings with a panel of experts in the cultural field that involved 18 members from public administration, companies, not-for-profit organisations and cultural institutions. Data collection is not separable from the activity in the field and arises from collaboration with the current and potential cultural entrepreneurs, discussion and solution of practical problems of emerging start-ups, teaching and mentoring, observation and notes collection.

The third step, the institutionalisation of the project, supports the critical reflection on the action taken and the reflective analysis of data and observation to build theory inductively. The researchers analysed data several times through a recursive cycle of data categorisation, comparison with the extant theory and discussion. Furthermore, in our analysis we found the use of excerpts highly worthwhile as they allow researchers to address the way the actors use language, think and make sense of the project.

Table 3 summarises research steps, data collection processes and the main output generated.

\section{Findings: the path creation of IncubiAmo cultura}

IncubiAmo Cultura is a pilot project that aims to nurture entrepreneurial education, mentoring potential entrepreneurs and offering incubation and acceleration for students' cultural start-ups. It is based on a pervasive process of knowledge translation, including the dissemination, exchange and application of specific knowledge tailored to the cultural sector. Figure 1 depicts the research steps already described in the previous Section.

Step 1 is a seminal phase of the project rooted in a European Project called Forget Heritage, a three-year-long program that started in June 2016 to identify innovative, replicable and sustainable public-private cooperation management models of the historical sites and urban districts.

The emerging research outcomes (labelled as a, b, c in Figure 1) outline that knowledge processes are at the basis of the development of a cultural ecosystem where grassroots initiatives and new ventures can be leveraged by education, cooperation with institutional actors and the dissemination of best practices to support a new round of initiatives. The interventionist researcher actively participated to both data collection through interviews and meetings, and findings implementation acting as mentor of a cultural start-up adopting best practices arising from the Forget Heritage project.

The Forget heritage project highlights the pivotal importance of knowledge circulation among the different actors aiming at cultural heritage valorisation (Maria T., General manager, Department for Culture and Leisure, City of Nuremberg)

Almost all of the examined cultural firms committed to cultural heritage preservation suggested innovative management models but lacked a solid knowledge base able to support their successful development. The educational gaps that have emerged from the survey show 
Step 1 (June 2016-June 2019) Step 2 (March 2018-June 2019) Step3 (March 2018-ongoing) Participation in the $\mathrm{FH}$ project University in action Institutionalisation

\begin{tabular}{|c|c|c|c|}
\hline $\begin{array}{l}\text { Research } \\
\text { step }\end{array}$ & $\begin{array}{l}\text { Forget Heritage EU project } \\
\text { aiming to identify innovative, } \\
\text { replicable and sustainable } \\
\text { Public Private Cooperation }\end{array}$ & $\begin{array}{l}\text { University in action } \\
\text { (translation in action of the } \\
\text { outcomes emerged from } \\
\text { step 1) }\end{array}$ & $\begin{array}{l}\text { Research outcomes } \\
\text { recombination and } \\
\text { Conceptual model design }\end{array}$ \\
\hline
\end{tabular}

\section{4} management models of the historical sites by valorising them through setting up Cultural and Creative

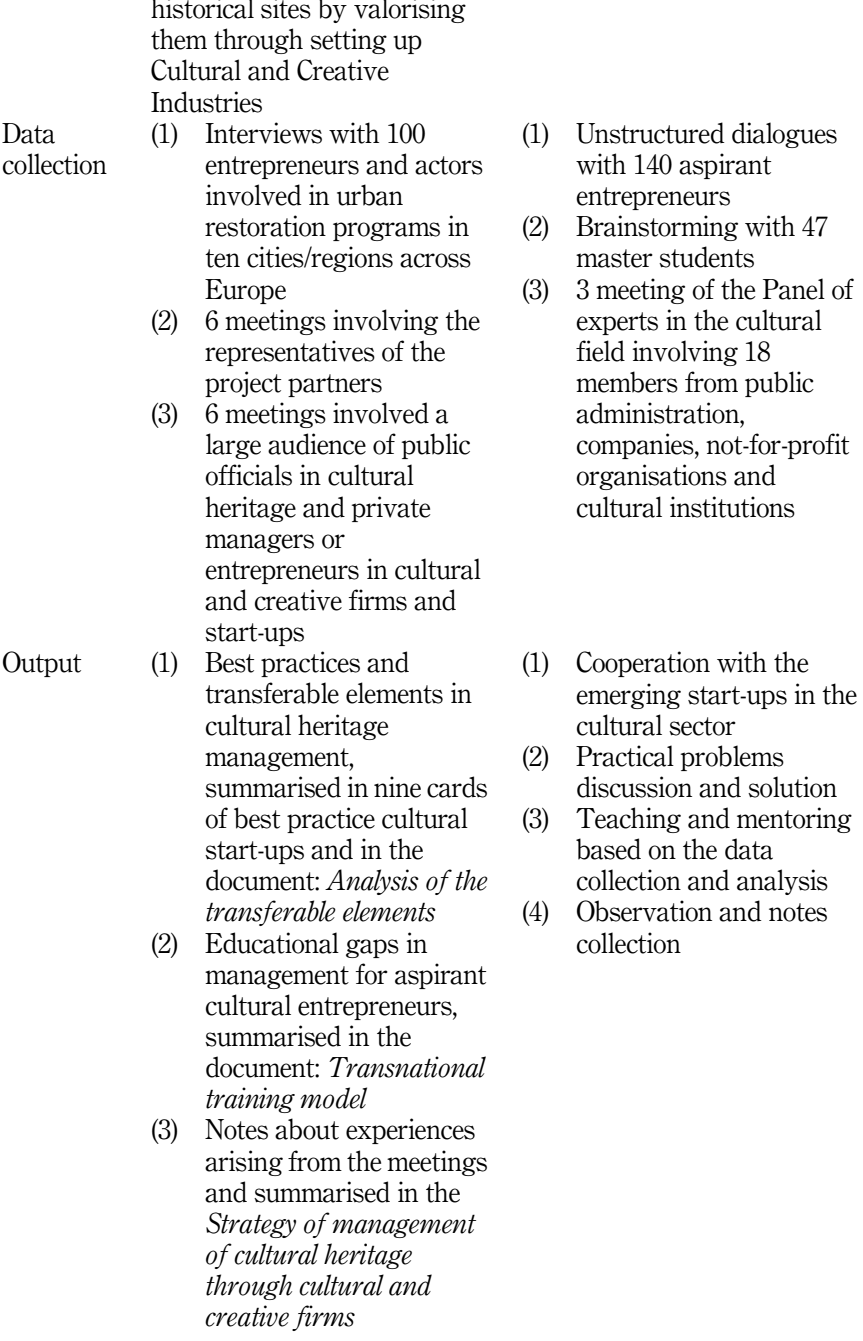

(1) Use of data collected in the previous steps

(2) Data and knowledge recombination

(3) Independent reading of all the materials from all the authors

(4) Comparison and discussion
Table 3.

Research steps, data collection processes and output

us that the required knowledge is not theoretical but a mix of both conceptualisations and best practices.

Tailored pilot projects of knowledge translation can be an effective instrument that emerge from the mix of best practices, conceptual models suggested by the university partners and the needs arising 

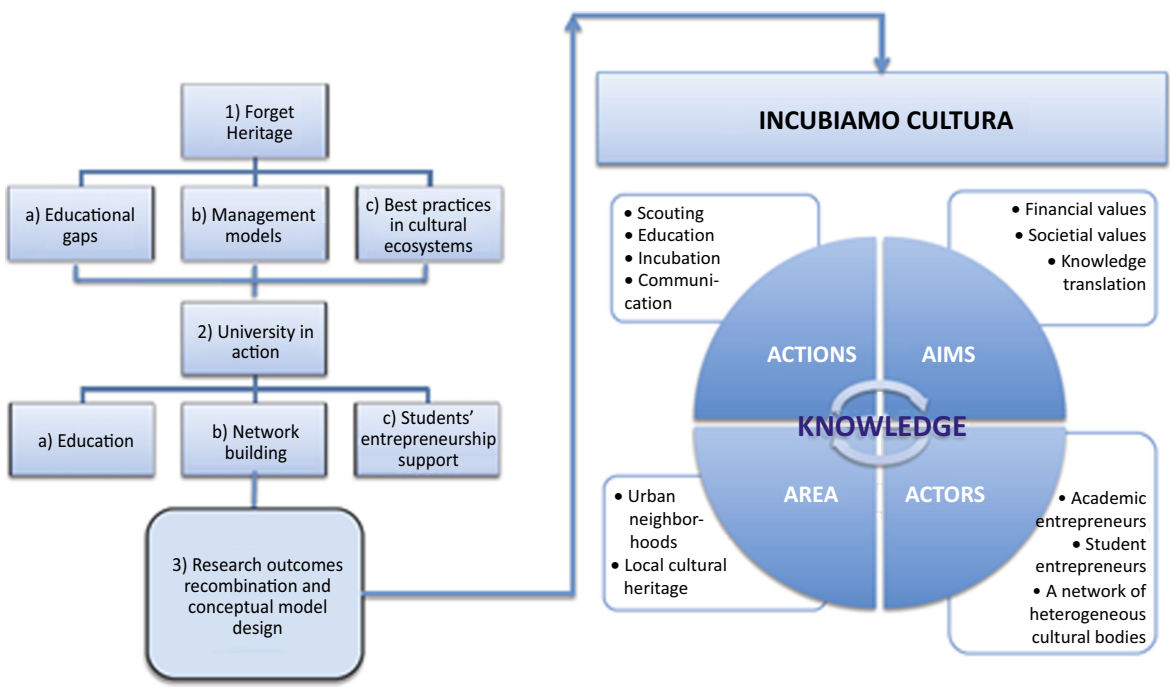

Knowledge in cultural ecosystems

1895

from cultural entrepreneurs and citizens (Guido G., General Manager, Department of Culture, Municipality of Genoa).

Moreover, it has become apparent that successful management models were based on cooperative strategies, involving both innovative startups and public organisations, both local administrations and cultural institutions. However, all the actors revealed the difficulty in translating their knowledge and experience into practice, because a pivotal actor able to convey those knowledge flows into a common sense was missing.

The Forget Heritage project helped us understand our strengths and weaknesses; as per urban regeneration projects, the lack of a cultural guide able to give meaning to our efforts and to lead the different actors to reach common goals is one of the main obstacles in our work (Director of Utopiastadt, a cultural start-up in Wuppertal, Germany).

Building on these findings, in Step 2 the university took action and - with the aim to contribute to the regional development - coherently launched a set of interrelated activities. The aim of these initiatives was to root the educational activity in a knowledge translation process able to overcome the traditional one-way knowledge flow that characterises academic education. The main idea was to implement an educational program based on circular knowledge flows, mixing theory and best practices, and rooted into a relational milieu involving heterogeneous actors: public administration, cultural institutions, cultural firms, students aspirant entrepreneurs, and innovative start-ups. The interventionist researcher has been the director of these initiatives; she built the educational activity based on all the educational gaps and the transferable elements emerged from the Forget Heritage project; moreover, she enlarged the knowledge base collecting data from the unstructured dialogues with aspirant cultural entrepreneurs and directing the panel of experts.

As aspirant entrepreneur in the cultural sector, my main problem is finding a common language to communicate with both the public administration and citizens and to find a way to share aims and efforts, pursuing business and cultural goals at the same time (Silvia, an aspirant entrepreneur attending the master class).

However, until then, this project lacked an integrated vision. Therefore, in step 3, the entrepreneurial academic consolidated and institutionalised the path mentioned above, by 
designing a framework to support entrepreneurial activities in the cultural field and deliver value to the territory in the medium-long term. The framework design is the final outcome of the journey; the double role of interventionist researcher and academic entrepreneur permitted to collect, process, and use data and knowledge in a virtuous fast cycle, transferring on the ground the best practices thanks to a continuous formal and informal exchange with colleagues, students, experts, entrepreneurs, and local politicians.

Hence this journey ended in the implementation of the project IncubiAmo Cultura, which was launched in 2018 and is still ongoing. IncubiAmo Cultura is based on four interconnected pillars - Area, Actors, Actions and Aims - and based upon knowledge circulation, as it will be explained in the following and summarised by some expressive and meaningful excerpts.

(1) Area: IncubiAmo Cultura is placed in a well-defined geographical area, that is, the Municipality of Genoa and its surroundings. The initiative aims to create physical spaces of co-working in urban areas and neighbourhoods where cultural and creative start-ups can work in close relationship with citizens, to restore abandoned cultural assets and deliver cultural initiatives (Rinaldi et al., 2018). The role of the space is not only geographic but also ecological, in that it primarily supports the interactions and relationships between the members of the cultural ecosystem, which is characterised by a shared cultural identity. The main aim of this pillar is to create a space where knowledge is continuously translated into action thanks to circular, recursive knowledge exchange and dissemination.

The link between the cultural heritage sites and the entrepreneurial activity is the translation into action of principles of heritage preservation and valorisation (Simona L., Director of the real estate management office at the Municipality of Genoa and member of the expert panel for cultural entrepreneurship in Genoa).

(2) Actors: cultural entrepreneurship requires special patterns of collaboration between diverse actors, such as the local government, profit and not-for-profit organisations, citizens, district communities, neighbourhood committees and other actors of the civil society. This peculiar aspect determines the crucial role of local networks in the knowledge flow. The micro and unstructured relationships between individuals, indeed, generate social capital and knowledge circulation that favour the spur of cultural ventures and initiatives. It is worth underlining that all the partners' representatives were involved in teaching or mentoring during the masterclasses and pitches. Even though it is possible to individuate some categories of actorsacademics, aspirant entrepreneurs/students, cultural experts, local politicians and public officers, cultural entrepreneurs-they play shifting roles because all of them are protagonists in the project. Hence, the aim of this pillar is to create a knowledge translation processes based on many-to-many relationships, where all the actors play interchangeable roles, overcoming the traditional linear knowledge transfer process.

IncubiAmo Cultura is a very interesting initiative for the university, as it both leverages entrepreneurship out of the traditional technology sector and outlines the differences between linear knowledge transfer and circular knowledge sharing. At the end, we'll have to change the name of our office! (Antonella P., Head of the Technology Transfer Office, University of Genoa).

(3) Actions: Students who attend a masterclass in entrepreneurship may strengthen their attitude, soft skills and competence to become entrepreneurs, but they have not got 
enough instruments to succeed in their venture. Launching a start-up requires mentoring and support and an ecosystem able to incubate the "new-born" firm. For this reason, the masterclass is only one step in building entrepreneurial capacity. The aim of this pillar is to implement processes tailored to cultural knowledge translation into action instead of technological knowledge transfer, therefore, based on knowledge sharing instead of knowledge patents. Thanks to IncubiAmo Cultura, which is a Living Lab of knowledge sharing, dissemination, exchange and application are not conceived as separate steps of knowledge translation but are merged together into a holistic approach within the project (Davis et al., 2003) and designed as a participatory action approach (McWilliam et al., 2009).

Before attending the masterclass, I was not really aware of the opportunity of entrepreneurship in the cultural sector. However, after attending the masterclass, I am now aware of how difficult it is to succeed without being part of a larger environment, where you can continuously exchange knowledge and best practices with both colleagues and professionals (Marianna, student and entrepreneur of a start-up incubated by IncubiAmo Cultura).

(4) Aims: Creating a cultural incubator is a complex initiative with a multi-faceted impact, and the hybrid nature of universities is crucial for supporting and spreading multiple values among actors and stakeholders. IncubiAmo Cultura pursues several shared goals regarding knowledge translation into action in the cultural field, aiming to create competitiveness in the cultural sector and promote social and cultural development concurrently. The aim of this pillar is to implement a community of actors who share their knowledge conceived as a common good, based on both research and empirical experience, pursuing a mix of economic, social and cultural goals.

I acknowledge that the masterclass was not only an educational activity but also a great territorial intervention, able to create a community that supports entrepreneurship in the cultural sector and to speed-up the our region's economy (Ilaria Cavo, Regional Counsellor for Education and Cultural heritage, Liguria Region).

\section{Discussion}

Starting from the research gaps highlighted above, several findings that stem from empirical evidence are discussed below.

\subsection{The pivotal role of the university in building knowledge translation mechanisms in cultural ecosystems}

The first gap we addressed concerned the lack of inquiry into the role that an entrepreneurial university can play in building knowledge translation mechanisms in cultural ecosystems.

A University is a well-known and authoritative organisation (Rasmussen et al., 2014) able to collect a constellation of actors open to a participatory approach for knowledge sharing (Simeone et al., 2017a, b; Paoloni et al., 2019). In executing the activities planned in the project, the University has played an orchestrator role (Secundo et al., 2016b), engaging all the involved parties in an active commitment because of its core competences in team building. All this was possible thanks to the personal commitment of entrepreneurial academics (Meyer, 2003), envisaging specific avenues in the area of cultural entrepreneurship.

Knowledge in cultural ecosystems 
This action of combining the entrepreneurial university + entrepreneurial academic is of paramount importance in a cultural ecosystem, given some of its features depicted in our literature review and its clear emergence from the case study, such as:

(1) It is a fragmented system, composed of numerous heterogeneous actors, often of micro and small dimension, unable to link together to create a meso-organisation to join their efforts in supporting cultural initiatives; the university, given its authoritativeness and leadership, can put all of them together;

(2) In the cultural sector, so far, few private or public organisations are committed to sparse research activities; the entrepreneurial university can fill this gap and acts as a catalyst for knowledge combination (Fish et al., 2016).

Thus, our study demonstrates that thanks to tailored activities that support entrepreneurship in the cultural ecosystem, the university can act as a collective intelligent system (Secundo et al., 2016 b) as knowledge can flow in and out thanks to the active involvement of all the parties, overcoming the linear model of knowledge transfer from the university to the market, which is well expressed in the following excerpt:

We acknowledge that this academic initiative is the answer to the difficulty to keep together heterogeneous actors in the cultural ecosystems and share knowledge at all the levels: from students to the main experts and back (Paola S. Director, Superintendence of Cultural Heritage Genoa).

\subsection{The conceptual model for knowledge translation tailored to the spur of cultural start-ups and initiatives}

The empirical investigation confirmed the research assumptions that the framework on knowledge transfer already designed for hi-tech knowledge cannot be replicated in a cultural milieu.

A cultural ecosystem is a heterogeneous network of actors driven by a mix of different values - economic, social, cultural, ethical and aesthetic values - far beyond the mere exploitation of knowledge transfer for business (Throsby, 1999). To implement a model able to collect, combine and convey knowledge and support to cultural entrepreneurship for both competitiveness and quality of life in the territory, a new process chain has been defined (see Figure 2).

The first three stages - scouting, education and mentoring - create a sort of Talent Garden (Mariotti et al., 2017), where one can cultivate their talents and grow; the latter two incubation and acceleration - form a hub, where business ideas are nurtured and start-ups are supported by the entrepreneurial university, delivering services and competences.

Co-working is intended not only as a space or a new way to organise labour but especially as a tool for the development of a cultural community of creative entrepreneurs working in urban areas spread throughout the city (Hutton, 2006; Simonelli and Monna, 2019).

The process chain effectiveness is mainly based on the linking of a sequence of processes that aims to nurture a mix of economic and social values, in alignment with the cultural milieu of the ecosystem, through the activities that support entrepreneurship in the creative and cultural sector.

The main success factor of this initiative is the chain of processes, in which each process exploits the value created by its antecedent and feeds the value creation of the one that follows. As shown in Figure 2, the knowledge translation process is an incremental path starting from the selection of participants and ending with the acceleration of the created firms.

At the first stage, the university collects ideas and knowledge from the different actors of the local cultural ecosystem, then recombines them all to design appropriate services for the 


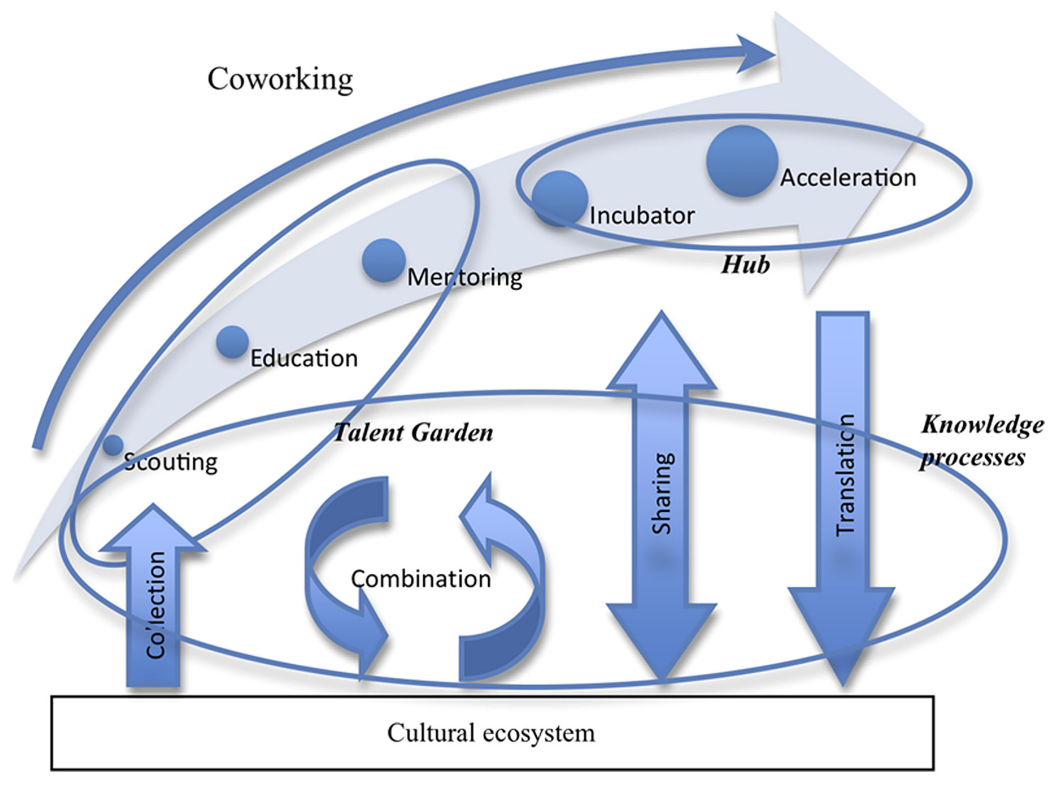

Knowledge in cultural ecosystems

1899

Figure 2.

The conceptual model for knowledge translation in a cultural ecosystem

spur of a cultural start-up. Thanks to testimonials, co-working and an open hub, knowledge is shared with all the partners, which is further recombined through a participatory and collaborative approach. Micro relations feed the continuous crowd collection of new tacit and explicit knowledge while cultural and creative start-ups translate knowledge into action, trigging a self-sustaining spiral of innovation and local development.

I came here to teach and I go back having learnt! (Serena B, Director of Palazzo Ducale and member of the panel of experts in cultural entrepreneurship)

\subsection{Knowledge translation: a double meaning}

The third gap concerned a need for unlocking how the role played by the university in translating knowledge is intended and deployed in the cultural ecosystem.

In our discussion, the knowledge flow activated by the IncubiAmo Cultura emerges as a non-linear process, thanks to the implementation of specific activities of knowledge collection, recombination and sharing. Knowledge is not simply transferred to the market but conveyed through the mediating role of an entrepreneurial university acting as collective intelligent system in a circular movement from the university to the cultural ecosystem and back, thanks to the collaboration with the territorial actors.

Knowledge translation is the outcome of a complex combination of actors, actions, values and the environment. Hence, in this specific ecosystem, our findings confirm that knowledge translation driven by the university has emerged with two different connotations which can be immediately perceived when referring to the metaphor of "catalyst" and "mediator".

On the one hand, it emerges as knowledge put into action, thanks to the design and implementation of a process chain, in which university acts as a catalyst, conveying knowledge to the spur of cultural start-ups, events and also grass-root initiatives, which, in turn, feeds a virtuous spiral of knowledge growth within the cultural ecosystem.

The effectiveness of this knowledge translation project lies in the fact that an entrepreneurial university, thanks to its recognised role, has the opportunity to leverage 
on a collaborative environment. Consequently, new business ideas proposed by aspiring entrepreneurs have the opportunity to be nurtured and assessed in the design phase, thanks to the expertise of cultural practitioners and entrepreneurs. This strengthens the relationships of aspiring entrepreneurs with the cultural ecosystem and feeds a process of knowledge transfer not only between actors but also over time (De Massis et al., 2016; Magistretti et al., 2020).

After the first cycle of masterclasses, 7 students out of 20 launched 3 new businesses; after the second cycle, 13 students out of 20 are founding 5 start-ups! (Monica B., professor of the master in cultural entrepreneurship)

On the other hand, it is knowledge translated into a shared language. IncubiAmo Cultura is a way to gather, translate and recombine different knowledge and experience in a finalised project understandable for all the involved subjects. Moreover, the dissemination of entrepreneurial and managerial "knowledge" translated into technical artefacts and tools (i.e., the design of a business model or a business plan, the drawing of an investments and funding plan or a pitch etc.) among potential cultural entrepreneurs and other stakeholders act as boundary objects to represent and accumulate knowledge from a wide variety of stakeholders (Bogers and Horst, 2014) and are a means to create shared sensemaking, which in turn can contribute to the enhancement of managerial skills in cultural ecosystems.

It is surprising how many different professionals - professors, entrepreneurs, public managers, artists, students, politicians, ... - are attending our pitches!" (Maurizio A., chartered accountant and manager of an incubator).

This is an important outcome of our inquiry as the lack of an entrepreneurial mind-set and managerial skills in the cultural sector was underlined by previous research a weakness for both cultural ecosystems and regional development (Borin and Donato, 2015).

\section{Conclusions, implications, limitations and further works}

Our work addresses the topic of knowledge translation processes in a collaborative environment such as that of a cultural ecosystem. As the potential role of the entrepreneurial university in enhancing local cultural ecosystems has been neglected both in practice and by the literature, notwithstanding the relevance of the cultural sector for our society, our inquiry aims to offer several contributions.

First, by combining two streams of research, namely cultural ecosystems (Borin and Donato, 2015) and universities as a collective intelligent system (Simeone et al., 2017a, b), never intersected until now, we aimed to understand how knowledge flows in the cultural sector at the meso level and, coherently, what role an entrepreneurial university could play to support cultural entrepreneurship.

Then, thanks to action research and critical reflection on case-based empirical evidences, the authors built a conceptual model for knowledge translation processes tailored to the cultural ecosystem. The whole process chain is thought up for an entrepreneurial university that is considered an intelligent system acting in a collaborative environment, involving various stakeholders who are committed to the enhancement of culture. At the interorganisational level, the university plays the role of orchestrator, which is necessary when actors are heterogeneous and unable to successfully design and manage integrated knowledge translation processes themselves.

In the specific context of application - the cultural sector - competitiveness is still an important goal. It does not only refer to a single firm unit but also to the meso-level such as that of a cultural ecosystem and a geographical area. However, other goals and values are 
pursued, such as aesthetic, ethical, cultural and social ones, and they influence the knowledge translation processes and the way they are implemented.

Collaborative dynamics and a participatory approach are critical success factors of these types of initiatives, and knowledge translation processes include several stages, such as knowledge collection, recombination, sharing and transfer. In each of these stages, all the actors play an active role, and the best results are reached thanks to a web of microrelationships.

The case study shows proof of the great differences between the knowledge transfer process in the hi-tech sector - linear transfer from the university to the market, by way of patents and academic spin-offs - and the knowledge circulation in the creative and cultural sector. In this case, knowledge flows are not linear but circular from the university to the environment and back several times, thanks to the open collaboration between the involved actors. Hence, in the conceptual model developed by the authors, university acts as a catalyst, by conveying spread knowledge and energies to the spur of cultural start-ups and initiatives and as a knowledge mediator, by providing common sensemaking based on the dissemination of entrepreneurial and managerial knowledge. Finally, while knowledge transfer in the hi-tech sector aims to speed up and rationalise innovation processes while protecting the knowledge thanks to patents, in the cultural sector, knowledge circulation aims for social innovation, widespread impact and long-term knowledge sedimentation since, at the end of the day, culture is a common good (Dameri and Moggi, 2019).

\subsection{Implications for research}

This article offers an important contribution to scholarship on knowledge translation by providing empirical research in a collaborative context, such as that of a cultural ecosystem. In doing so, it also contributes to the advancement of research on entrepreneurial university by proposing a conceptual model that aims to sustain and manage processes of knowledge translation in an environment that has been neglected by literature. What we deem is of particular interest to researchers in this field is the relevance of common values (i.e., social, cultural, ethical and aesthetic) that cultural actors share and that are the basis on which to build open innovation and knowledge circulation. For these reasons, the process chain effectiveness of the model of knowledge translation is mainly based on the linking of a sequence of processes that aims to nurture a mix of economic and social values, in alignment with the cultural milieu of the ecosystem.

\subsection{Implications for policymakers and universities}

For local policymakers looking to encourage beneficial practices for the enhancement of the cultural sector, the draft of our conceptual model provides a clue to understand that effective interventions need an integrated vision and policies that aim to make an impact at a cultural ecosystem level in the medium-long run. Spot actions, such as the financing of educational activities alone, may fail to reach the goal of knowledge translation, calling for a proactive role of an entrepreneurial university to engage several actors and act as a knowledge catalyst, a cultural mediator and, finally, an orchestrator of initiatives.

For university governance, our investigation offers food for thought on new challenges and opportunities to enlarge the implementation of the third mission to fields so far neglected. However, specific attention should be paid to tailoring knowledge translation processes that fit with the specificity of the cultural ecosystem context. Moreover, we deem that universities, thanks to their institutional legitimation, can play a more effective role in creating relationships and social capital to support urban culture-led regeneration interventions and smart-cities projects (Dameri et al., 2014), which in the last few years has emerged as a worldwide trend (Cooke and Lazzeretti, 2008; UN, 2013).
Knowledge in cultural ecosystems

1901 
In the same vein, practitioners in the cultural field should be aware that developing entrepreneurial orientation, managerial skills and networking competence is vital to face new challenges that emerge from the cultural sector, both at micro and meso levels, calling for a change in mindset. Active participation in this knowledge translation project can be an opportunity to increase the knowledge of all actors, as well as to raise awareness of the need to create networks, push innovation and increase managerial skills at all levels.

Moreover, through this path, aspiring entrepreneurs will not only acquire managerial skills but, thanks to their collaboration with practitioners, will have the opportunity to increase their network and place their business ideas under scrutiny, while still in the design and embryonic phase. Overall, the model for the knowledge translation is tailored to a cultural ecosystem, enabling business ideas to be nurtured by the different actors from within the cultural ecosystem and start-ups to be supported by the entrepreneurial university that delivers them shaped services and competences.

\subsection{Limitations and further research}

Limitations of this work should also be considered. First of all, the choice of the method, action research, is not free from subjectivity. However, in this study, one of the authors is the founder and orchestrator of the initiative, whereas the other author is not involved in the project but contributes as an external observer and discussant, who helped us overcome the limitation of the interventionist approach.

Then, we based the interpretation and discussion of the evidence referring to and combining, to this purpose, the main concepts of "cultural ecosystem" and "entrepreneurial university as collective intelligent system", which is part of our contribution to this field of research, but another lens could be appropriate.

Finally, the model developed here must be tested and refined in other contexts to more fully establish its validity and generalisability, even if positive intermediate goals have been reached successfully and all the actors have given positive feedback concerning the initiative. Hence, further work will address two main concerns. First is the examination of the environmental factors that can favour or constrain the institutionalisation of the model experimented through the pilot project within the university. The second regards the evaluation of the replicability of the project because "one swallow does not make a summer"; the pilot project should be communicated, participatory and especially replicated thanks to a protocol that is able to reproduce the experience in different cities, urban areas and neighbourhoods, to multiply the positive impacts.

\section{References}

Astebro, T. and Bazzazian, N. (2011), "Universities, entrepreneurship and local economic development", Handbook of Research on Entrepreneurship and Regional Development: National and Regional Perspectives, pp. 252-333.

Biondi, L., Demartini, P., Marchegiani, L., Marchiori, M. and Piber, M. (2020), "Understanding orchestrated participatory cultural initiatives: mapping the dynamics of governance and participation", Cities, Vol. 96, p. 102459.

Birnkraut, G. (2018), “The new socio-cultural entrepreneurs", Entrepreneurship in Culture and Creative Industries, Springer, Cham, pp. 171-182.

Bogers, M. and Horst, W. (2014), "Collaborative prototyping: cross-fertilization of knowledge in prototype-driven problem solving”, Journal of Product Innovation Management, Vol. 31 No. 4, pp. 744-764. 
Bonet, L. and Donato, F. (2011), "The financial crisis and its impact on the current models of governance and management of the cultural sector in Europe”, ENCATC Journal of cultural management and policy, Vol. 1 No. 1, pp. 4-11.

Borin, E. and Donato, F. (2015), "Unlocking the potential of IC in Italian cultural ecosystems", Journal of Intellectual Capital, Vol. 16 No. 2, pp. 285-304.

Borin, E. and Delgado, E.J. (2018), "The value of cultural and regional identity: an exploratory study of the viewpoints of funders and cultural and creative entrepreneurs", ENCATC Journal of Cultural Management and Policy, Vol. 8 No. 1, pp. 16-29.

Borin, E., Donato, F. and Sinapi, C. (2018), "Financial sustainability of small-and medium-sized enterprises in the cultural and creative sector: the role of funding", in Innerhofer, E., Pechlaner, H. and Borin, E. (Eds), Entrepreneurship in Culture and Creative Industries, Springer, Cham, pp. $45-62$.

Botes, L. (2005), "Beyond@ Ivory. Tower-from traditional university to engaged university", Proceedings of United Nations Conference on Engaging Communities.

Canterino, F., Shani, A.B., Coghlan, D. and Brunelli, M.S. (2016), "Collaborative management research as a modality of action research: learning from a merger-based study", The Journal of Applied Behavioral Science, Vol. 52 No. 2, pp. 157-186.

Clark, B. (2001), "The entrepreneurial university: new foundations for collegiality, autonomy, and achievement", Higher Education Management, Vol. 13 No. 2.

Cocchia, A. and Dameri, R.P. (2016), "Exploring smart city vision by university, industry and government", in D'Ascenzo, F., Magni, M., Lazazzara, A. and Za, S. (Eds), Blurring the Boundaries through Digital Innovation. Lecture Notes in Information Systems and Organisation, Springer, Cham, Vol. 19, doi: 10.1007/978-3-319-38974-5_20.

Cooke, P.N. and Lazzeretti, L. (Eds) (2008), Creative Cities, Cultural Clusters and Local Economic Development, Edward Elgar Publishing.

Dameri, R.P. and Moggi, S. (2019), "Emerging business models for the cultural commons. Empirical evidence from creative cultural firms", Knowledge Management Research and Practice, pp. 1-14, doi: 10.1080/14778238.2019.1664945.

Dameri, R.P., Ricciardi, F. and D’Auria, B. (2014), Knowledge and Intellectual Capital in Smart City, European Conference on Knowledge Management, Kidmore End, pp. 250-257.

Davis, D., Evans, M., Jadad, A., Perrier, L., Rath, D., Ryan, D., Sibbald, G., Straus, S., Rappolt, S., Wowk, M. and Zwarenstein, M. (2003), "The case for knowledge translation: shortening the journey from evidence to effect", BMJ, Vol. 327 No. 7405, pp. 33-35.

De Massis, A., Frattini, F., Kotlar, J., Petruzzelli, A.M. and Wright, M. (2016), "Innovation through tradition: lessons from innovative family businesses and directions for future research", Academy of Management Perspectives, Vol. 30 No. 1, pp. 93-116.

Degen, M. and García, M. (2012), “The transformation of the 'Barcelona model': an analysis of culture, urban regeneration and governance", International Journal of Urban and Regional Research, Vol. 36 No. 5, pp. 1022-1038.

Eisenhardt, K.M. (1989), "Building theories from cases”, Academy of Management Review, Vol. 14 No. 1, pp. 532-550.

Eisenhardt, K.M. and Graebner, M.E. (2007), "Theory building from cases”, Opportunities and Challenges, Vol. 50 No. 1, pp. 25-32.

Ellmeier, A. (2003), "Cultural entrepreneurialism: on the changing relationship between the arts, culture and employment1", International Journal of Cultural Policy, Vol. 9 No. 1, pp. 3-16.

Essig, L. (2014a), "Ownership, failure, and experience: goals and evaluation metrics of universitybased arts venture incubators", Entrepreneurship Research Journal, Vol. 4 No. 1, pp. 117-135, doi: 10.1515/erj-2013-0037.
Knowledge in cultural ecosystems

1903 
Essig, L. (2014b), “Arts incubators: a typology”, The Journal of Arts Management, Law, and Society, Vol. 44 No. 3, pp. 169-180.

Etzkowitz, H. (2003), "Research groups as 'quasi-firms': the invention of the entrepreneurial university”, Research Policy, Vol. 32 No. 1, pp. 109-121.

Fayolle, A. and Redford, D.T. (2014), Handbook on the Entrepreneurial University, Edward Elgar Publishing, Cheltenham.

Fish, R., Church, A. and Winter, M. (2016), "Conceptualising cultural ecosystem services: a novel framework for research and critical engagement”, Ecosystem Services, Vol. 21, pp. 208-217.

Florida, R. (1999), "The role of the university: leveraging talent, not technology", Issues in Science and Technology, Vol. 15 No. 4, pp. 67-73.

Fontana, R., Geuna, A. and Matt, M. (2006), "Factors affecting university-industry R\&D projects: the importance of searching, screening and signalling”, Research Policy, Vol. 35 No. 2, pp. 309-323.

Friedman, J. and Silberman, J. (2003), "University technology transfer: do incentives, management, and location matter?", Journal of Technology Transfer, Vol. 28 No. 1, pp. 17-30.

Glaser Barney, G. and Strauss Anselm, L. (1967), The Discovery of Grounded Theory: Strategies for Qualitative Research, Adline de Gruyter, New York.

Grigoriou, K. and Rothaermel, F.T. (2014), "Structural microfoundations of innovation: the role of relational stars", Journal of Management, Vol. 40 No. 2, pp. 586-615.

Guerrero, M. and Urbano, D. (2012), "The development of an entrepreneurial university", The Journal of Technology Transfer, Vol. 37 No. 1, pp. 43-74.

Guerrero, M., Urbano, D., Fayolle, A., Klofsten, M. and Mian, S. (2016), "Entrepreneurial universities: emerging models in the new social and economic landscape", Small Business Economics, Vol. 47 No. 3, pp. 551-563.

Gulbrandsen, M. and Slipersaeter, S. (2007), "The third mission and the entrepreneurial university model", in Bonaccorsi, A. and Daraio, C. (Eds), Universities and Strategic Knowledge Creation: Specialization and Performance in Europe, Edward Elgar Publishing, Chesterton, pp. 112-143.

Haigh, N., Walker, J., Bacq, S. and Kickul, J. (2015), "Hybrid organizations: origins, strategies, impacts, and implications", California Management Review, Vol. 57 No. 3, pp. 5-12.

Hayter, C.S. (2016), "A trajectory of early-stage spinoff success: the role of knowledge intermediaries within an entrepreneurial university ecosystem", Small Business Economics, Vol. 47 No. 3, pp. 633-656.

Hockerts, K. (2015), "How hybrid organizations turn antagonistic assets into complementarities", California Management Review, Vol. 57 No. 3, pp. 5-12.

Holden, J. (2015), "The ecology of culture. A report commissioned by the arts and Humanities research council's cultural value project", available at: http://www.publicartonline.org.uk/downloads/ news/AHRC Ecology of Culture.pdf (accessed May 2019).

Hutton, T.A. (2006), "Spatiality, built form, and creative industry development in the inner city", Environment and Planning A, Vol. 38 No. 10, pp. 1819-1841.

Jönsson, S. and Lukka, K. (2006), "There and back again: doing interventionist research in management accounting", Handbooks of management accounting research, Vol. 1, pp. 373-397.

Kachra, A. and White, R.E. (2008), "Know-how transfer: the role of social, economic/competitive, and firm boundary factors", Strategic Management Journal, Vol. 29 No. 4, pp. 425-445.

Kingma, B.R. (Ed.) (2011), Academic Entrepreneurship and Community Engagement: Scholarship in Action and the Syracuse Miracle, Edward Elgar Publishing.

Köhler, C., Sofka, W. and Grimpe, C. (2012), "Selective search, sectoral patterns, and the impact on product innovation performance", Research Policy, Vol. 41 No. 8, pp. 1344-1356.

Kogut, B. and Zander, U. (1992), "Knowledge of the firm, combinative capabilities, and the replication of technology”, Organization Science, Vol. 3 No. 3, pp. 383-397. 
Kogut, B. and Zander, U. (1993), "Knowledge of the firm and the evolutionary theory of the multinational corporation”, Journal of International Business Studies, Vol. 24 No. 4, pp. 625-645.

Laursen, K. and Salter, A. (2004), "Searching high and low: what types of firms use universities as a source of innovation?”, Research Policy, Vol. 33 No. 8, pp. 1201-1215.

Leardini, C., Rossi, G., Moggi, S. and Zardini, A. (2017), "When the law shapes nonprofit boards: the key role of local stakeholders", Nonprofit and Voluntary Sector Quarterly, Vol. 46 No. 1, pp. $47-70$.

Lee, M. and Jay, J. (2015), "Strategic responses to hybrid social ventures", California Management Review, Vol. 57 No. 3, pp. 5-12.

Leimeister, J.M. (2010), “Collective intelligence”, Business and Information Systems Engineering, Vol. 2 No. 4, pp. 245-248.

Lewin, K. (1946), “Action research and minority problems", Journal of Social Issues, Vol. 2 No. 4, pp. 34-46.

Magistretti, S., Dell'Era, C. and Doppio, N. (2020), "Design sprint for SMEs: an organizational taxonomy based on configuration theory", Management Decision, ahead of print. doi: 10.1108/ MD-10-2019-1501.

Mariotti, I., Pacchi, C. and Di Vita, S. (2017), "Co-working spaces in Milan: location patterns and urban effects”, Journal of Urban Technology, Vol. 24 No. 3, pp. 47-66.

McWilliam, C.L., Kothari, A., Ward-Griffin, C., Forbes, D., Leipert, B. and South West Community Care Access Centre Home Care Collaboration (SW-CCAC) (2009), "Evolving the theory and praxis of knowledge translation through social interaction: a social phenomenological study", Implementation Science, Vol. 4 No. 1, p. 26.

Meyer, M. (2003), "Academic entrepreneurs or entrepreneurial academics? Research-based ventures and public support mechanisms", $R \&$ D Management, Vol. 33 No. 2, pp. 107-115.

Nakauchi, M., Washburn, M. and Klein, K. (2017), "Differences between inter-and intra-group dynamics in knowledge transfer processes", Management Decision, Vol. 55 No. 4, pp. 766-782.

OECD (2012), A Guiding Framework for, Entrepreneurial Universities, Paris.

Pagano, A., Petrucci, F. and Bocconcelli, R. (2018), "A business network perspective on unconventional entrepreneurship: a case from the cultural sector", Journal of Business Research, Vol. 92, pp. $455-464$.

Paoloni, P., Cesaroni, F.M. and Demartini, P. (2019), "Relational capital and knowledge transfer in universities”, Business Process Management Journal, Vol. 25 No. 1, pp. 185-201.

Petrova, L. (2018), "Cultural entrepreneurship in the context of spillovers within within the cultural and creative industries", Entrepreneurship in Culture and Creative Industries, Springer, Cham, pp. 197-211.

Piber, M., Demartini, P. and Biondi, L. (2019), “The management of participatory cultural initiatives: learning from the discourse on intellectual capital", Journal of Management and Governance, Vol. 23 No. 2, pp. 435-458.

Powell, W.W. and Snellman, K. (2004), "The knowledge economy”, Annual Review of Sociology, Vol. 30, pp. 199-220.

Pugh, R., Soetanto, D., Jack, S.L. and Hamilton, E. (2019), "Developing local entrepreneurial ecosystems through integrated learning initiatives: the Lancaster case", Small Business Economics, ahead of print, pp. 1-15.

Rasmussen, B. and Lynov, J.P. (2005), "Musicon Valley-reflections on innovative alliances involving technological research and the cultural sector", International Conference on. Regional Studies Association.

Rasmussen, E., Mosey, S. and Wright, M. (2014), "The influence of university departments on the evolution of entrepreneurial competencies in spin-off ventures", Research Policy, Vol. 43 No. 1, pp. 92-106. 
Rinaldi, C., Cavicchi, A., Spigarelli, F., Lacchè, L. and Rubens, A. (2018), "Universities and smart specialisation strategy", International Journal of Sustainability in Higher Education.

Rice, M.P., Fetters, M.L. and Greene, P.G. (2014), "University-based entrepreneurship ecosystems: a global study of six educational institutions", International Journal of Entrepreneurship and Innovation Management, Vol. 18 Nos 5-6, pp. 481-501.

Sacco, P. and Tavano Blessi, G. (2009), "The social viability of culture-led urban transformation processes: evidence from the Bicocca District, Milan”, Urban Studies, Vol. 46 Nos 5-6, pp. 1115-1135.

Savino, T., Messeni Petruzzelli, A. and Albino, V. (2017), "Search and recombination process to innovate: a review of the empirical evidence and a research agenda", International Journal of Management Reviews, Vol. 19, pp. 54-75, doi: 10.1111/ijmr.12081.

Schiuma, G. (2011), The Value of Arts for Business, Cambridge University Press, Cambridge.

Secundo, G., De Beer, C. and Passiante, G. (2016a), "Measuring university technology transfer efficiency: a maturity level approach", Measuring Business Excellence, Vol. 20 No. 3, pp. 42-54.

Secundo, G., Dumay, J., Schiuma, G. and Passiante, G. (2016b), "Managing intellectual capital through a collective intelligence approach: an integrated framework for universities", Journal of Intellectual Capital, Vol. 17 No. 2, pp. 298-319.

Secundo, G., Perez, S.E., Martinaitis, Ž. and Leitner, K.H. (2017), "An Intellectual Capital framework to measure universities' third mission activities", Technological Forecasting and Social Change, Vol. 123, pp. 229-239.

Siggelkow, N. (2007), "Persuasion with case study", Academy of Management Journal, Vol. 50 No. 1, pp. 20-24.

Simeone, L., Secundo, G. and Schiuma, G. (2017a), "Fostering academic entrepreneurship through design-as-translation to align stakeholders' needs: the MIT Senseable city lab case", Technovation, Vols 64-65, pp. 58-67.

Simeone, L., Secundo, G. and Schiuma, G. (2017b), "Knowledge translation mechanisms in open innovation: the role of design in R\&D projects", Journal of Knowledge Management, Vol. 21 No. 6, pp. 1406-1429.

Simeone, L., Secundo, G. and Schiuma, G. (2018), "Arts and design as translational mechanisms for academic entrepreneurship: the metaLAB at Harvard case study", Journal of Business Research, Vol. 85, pp. 434-443.

Secundo, G., Massaro, M., Dumay, J. and Bagnoli, C. (2018), "Intellectual capital management in the fourth stage of IC research: a critical case study in university settings", Journal of Intellectual Capital, Vol. 19 No. 1, pp. 157-177.

Simonelli, G. and Monna, V. (2019), Co-working: Working Spaces in a Liquid Society. Living, Working and Travelling: New Processes of Hybridization for the Spaces of Hospitality and Work, Franco Angeli, Milano, Vol. 69.

Strike, V.M. and Rerup, C. (2016), "Mediated sensemaking", Academy of Management Journal, Vol. 59 No. 3, pp. 880-905.

Suomala, P. (2009), "Interventionist research-contributing to management accounting through industry-university collaboration”, Research Update, Vol. 2009 March, pp. 10-11.

Throsby, D. (1999), "Cultural capital”, Journal of Cultural Economics, Vol. 23 Nos 1-2, pp. 3-12.

United Nations/UNDP/UNESCO (2013), Creative Economy Report, Special Edition, Widening Local Development Pathways, Published by the United Nations Development Programme (UNDP), One United Nations , and the United Nations Educational, Scientific and Cultural Organization (UNESCO), available at: http://www.unesco.org/culture/pdf/creative-economy-report-2013.pdf (accessed January 2019).

Verona, G. and Ravasi, D. (2003), "Unbundling dynamic capabilities: an exploratory study of continuous product innovation", Industrial and Corporate Change, Vol. 12 No. 3, pp. 577-606. 
Wright, M. (2014), “Academic entrepreneurship, technology transfer and society: where next?”, The Journal of Technology Transfer, Vol. 39 No. 3, pp. 322-334.

Yin, R.K. (1994), Case Study Research: Design and Methods, Sage, Newbury Park CA.

Yusof, M. and Jain, K.K. (2010), "Categories of university-level entrepreneurship: a literature survey", The International Entrepreneurship and Management Journal, Vol. 6 No. 1, pp. 81-96.

Zander, U. and Kogut, B. (1995), "Knowledge and the speed of the transfer and imitation of organizational capabilities: an empirical test”, Organization Science, Vol. 6 No. 1, pp. 76-92.
Knowledge in cultural ecosystems

\section{Sitography}

FH1, https://www.interreg-central.eu/Content.Node/Forget-Heritage/D.T1.1.3-Analysisof-the-transferable-elements-of-the-BPs.pdf

FH 2, https://www.interreg-central.eu/Content.Node/Forget-heritage.html

FH3, https://www.interreg-central.eu/Content.Node/Forget-heritage.html

FH4, https://www.interreg-central.eu/Content.Node/Forget-heritage.html

\section{Further reading}

Morris, M.H., Shirokova, G. and Tsukanova, T. (2017), "Student entrepreneurship and the university ecosystem: a multi-country empirical exploration", European Journal of International Management, Vol. 11 No. 1, pp. 65-85.

\section{Corresponding author}

Renata Paola Dameri can be contacted at: dameri@economia.unige.it

For instructions on how to order reprints of this article, please visit our website:

www.emeraldgrouppublishing.com/licensing/reprints.htm

Or contact us for further details: permissions@emeraldinsight.com 